\title{
Experimental selection for ivermectin resistance in Ostertagia ostertagi in cattle
}

\author{
A.M. Van Zeveren ${ }^{a}$, S. Casaert ${ }^{a}$, M. Alvinerie ${ }^{b}$, P. Geldhof ${ }^{\mathrm{a}, *}$, \\ E. Claerebout ${ }^{\mathrm{a}}, \mathrm{J}$. Vercruysse ${ }^{\mathrm{a}}$ \\ ${ }^{a}$ Laboratory for Parasitology, Faculty of Veterinary Medicine, Ghent University, Salisburylaan 133, 9820 Merelbeke, Belgium \\ ${ }^{\mathrm{b}}$ Laboratoire de Pharmacologie-Toxicologie, INRA, 180 Chemin de Tournefeuille, BP3, 31931 Toulouse Cedex 9, France
}

Received 25 June 2007; received in revised form 27 August 2007; accepted 7 September 2007

\begin{abstract}
Recent reports of suspected ivermectin (IVM) resistance in Ostertagia ostertagi have highlighted the need for research into the mechanisms of IVM resistance. However, there are no reports of resistant field isolates of $O$. ostertagi, which have been characterized for molecular research. Therefore, an anthelmintic susceptible $O$. ostertagi population was selected for IVM resistance by repeatedly exposing the population to subtherapeutic and therapeutic levels of IVM over 10 generations. In each selection round, a group of calves was infected with the progeny of the previous IVM-selected $O$. ostertagi population. In the last selection round a therapeutic IVM dose $(0.2 \mathrm{mg} / \mathrm{kg} \mathrm{BW})$ only reduced the faecal egg counts by $57 \%$ and $65 \%$ on days 7 and 14 after treatment, respectively. In contrast, the therapeutic IVM dose was $100 \%$ effective at eliminating the parental IVM-susceptible isolate.
\end{abstract}

(C) 2007 Elsevier B.V. All rights reserved.

Keywords: Ostertagia ostertagi; Nematode; Anthelmintic resistance; Macrocyclic lactones; Ivermectin; Selection

\section{Introduction}

The introduction of ivermectin (IVM) in 1981, a macrocyclic lactone (ML) which has excellent broadspectrum activity against nematodes and several parasitic arthropods, opened new markets and new management options for parasite control. However, the intensive and frequent use of these anthelmintics has resulted in the development of ML resistance in several hosts (Geary, 2005; Kaplan, 2004; McKellar and Jackson, 2004). In small ruminants, anthelmintic-resistant nematodes are already a serious problem worldwide (Jackson and Coop, 2000). IVM resistance was first reported in Haemonchus contortus and later in Teladorsagia circumcincta and

\footnotetext{
* Corresponding author. Tel.: +32 92647400; fax: +32 92647496 .

E-mail address: peter.geldhof@UGent.be (P. Geldhof).
}

Trichostrongylus colubriformis (Kaplan, 2004). Reports of ML resistance in nematodes of cattle have been less common, and the general belief is that resistance is not yet an important issue in this host (Kaplan, 2004). However, reports of ML-resistant nematodes in cattle are emerging in several parts of the world and resistance will probably become more widespread. In recent years, ML resistance in Cooperia spp. has become increasingly common in Brazil (Echevarria and Pinheiro, 1999), Argentina (Anziani et al., 2001; Fiel et al., 2001; Mejia et al., 2003), New Zealand (Familton et al., 2001; Loveridge et al., 2003; Vermunt et al., 1996), the US (Gasbarre et al., 2004) and the UK (Coles et al., 1998, 2001). To date, the first cases of suspected emerging IVM resistance in $O$. ostertagi are reported in New Zealand (Mason and McKay, 2006; Waghorn et al., 2006) and Argentina (Suarez and Cristel, 2007). These reports have 
not yet been confirmed with controlled field studies. In the light of these recent findings ML resistance in $O$. ostertagi might be more common than currently recognized. Therefore, it is important to investigate the increase in resistance alleles before ML resistance in $O$. ostertagi is widespread. Due to the lack of sensitive tests, the detection of anthelmintic resistance is currently not possible at an early stage. The development of sensitive molecular tests requires knowledge of the mechanisms of ML resistance, but no resistant field isolates of $O$. ostertagi has been characterized for molecular research. For that reason, the aim of this study was to experimentally select a laboratory IVM-resistant $O$. ostertagi isolate in cattle. In the near future, this IVMresistant isolate, derived from a parental IVM-susceptible isolate, will be used to examine the mechanisms of ML resistance in $O$. ostertagi in cattle.

\section{Materials and methods}

\subsection{Parasite isolates}

The anthelmintic susceptible parental $O$. ostertagi population was initially isolated from a commercial Belgian dairy farm in 1987 and stored in liquid nitrogen until 1993. Thereafter the population was maintained in the laboratory by passage through helminth-free calves.

\subsection{Experimental trial design}

An anthelmintic susceptible $O$. ostertagi population was selected for IVM resistance by repeatedly exposing the population to subtherapeutic and therapeutic levels of IVM over 10 generations. For each trial helminthfree Holstein-cross-breed calves between 5 and 8 months old were orally infected with 50,000 infective larvae $(2 \times 25,000 \mathrm{~L} 3$ in $10 \mathrm{ml}$ tap water). The calves were fed maize silage and hay ad libitum and had free access to drinking water.

In the first selection round sixteen helminth-free calves, infected with the parental IVM-susceptible $O$. ostertagi isolate (IVMS), were randomized over four groups of four animals based on their egg counts on day 25 post-infection. The animals were weighted twice (days 24 and 25 post-infection) with a balance calibrated with an accuracy of $1 \mathrm{~kg}$. On day 25 after infection each group of calves was treated subcutaneously with a different subtherapeutic IVM dose $(0.1$, $0.05,0.025$ and $0.0125 \mathrm{mg} / \mathrm{kg}$ Ivomec Merial $^{\circledR}$ ) to assess the efficacy of IVM against the IVMS isolate. The IVM dose was calculated based on the mean weight of all the animals on days 24 and 25 post-infection. Blood samples were collected from each calf on 2, 5 and 10 days post-treatment to determine the IVM plasma levels. Faecal egg counts (FEC) were performed on day 25 after infection and weekly (on 7, 14, 21 days) after IVM treatment. To obtain the infective third-stage larvae (L3) for the next generation, the total faecal output of the group of calves which gave the desired egg count reduction $(<95 \%$ FEC reduction for the first selection round) was collected from days 3-21 posttreatment and cultured. Infective L3 were collected using baermannisation. The L3 progeny of the first five and the eight selection rounds was passaged through a helminth-free calf to produce sufficient infective larvae for the sequential selection round. For each sequential selection round, a group of calves was infected with the progeny of the previous IVM-selected $O$. ostertagi isolate $(2 \times 25,000 \mathrm{~L} 3 \mathrm{in} 10 \mathrm{ml}$ tap water) (Table 1). The IVM doses gradually increased from 0.0125 to $0.2 \mathrm{mg} /$

Table 1

Overview of the sequential selection rounds: the number of calves per selection round, the IVM doses, area under the curve (AUC value) of the IVM plasma concentration, the percentage reduction in faecal egg counts (FEC) on days 7, 14 and 21 post-treatment

\begin{tabular}{|c|c|c|c|c|c|c|}
\hline $\begin{array}{l}\text { Selection } \\
\text { round }\end{array}$ & $\begin{array}{l}\text { Number of } \\
\text { calves }\end{array}$ & $\begin{array}{l}\text { IVM dose } \\
(\mathrm{mg} / \mathrm{kg} \mathrm{BW})\end{array}$ & $\begin{array}{l}\text { AUC of IVM plasma } \\
\left(\text { ng day } \mathrm{ml}^{-1}\right)( \pm \text { S.D. })\end{array}$ & $\begin{array}{l}\text { Reduction in FEC } \\
\text { on day } 7(\%) \text { (range) }\end{array}$ & $\begin{array}{l}\text { Reduction in FEC } \\
\text { on day } 14(\%) \text { (range) }\end{array}$ & $\begin{array}{l}\text { Reduction in FEC } \\
\text { on day } 21(\%) \text { (range) }\end{array}$ \\
\hline 1 & 4 & 0.0125 & $13.7( \pm 1.9)$ & $94.9(93-98)$ & $88.2(71-94)$ & $93.1(86-98)$ \\
\hline 2 & 6 & 0.025 & $30.7( \pm 9.9)$ & $94.5(79-100)$ & $93.4(79-100)$ & $86.8(79-100)$ \\
\hline 3 & 5 & 0.05 & $74.3( \pm 33.5)$ & $100(100-100)$ & $99.5(98-100)$ & $100(100-100)$ \\
\hline 4 & 4 & 0.075 & $52.9( \pm 20.0)$ & $76.1(50-100)$ & $70.0(0-100)$ & $56.9(0-100)$ \\
\hline 5 & 4 & 0.1 & $87.3( \pm 42.1)$ & $99.2(98-100)$ & $99.3(98-100)$ & $99.1(98-100)$ \\
\hline 6 & 3 & 0.1 & $86.8( \pm 35.7)$ & 70.5 (25-96) & $65.9(25-91)$ & 81.3 (50-99) \\
\hline 7 & 3 & 0.1 & $98.1( \pm 19.6)$ & $89.0(71-98)$ & $88.8(70-98)$ & $81.5(50-98)$ \\
\hline 8 & 5 & 0.2 & $111.1( \pm 48.8)$ & $90.0(50-100)$ & $79.5(0-100)$ & $\mathrm{ND}^{\mathrm{a}}$ \\
\hline 9 & 6 & 0.2 & $252.9( \pm 58.2)$ & $87.8(50-100)$ & $91.6(75-100)$ & $\mathrm{ND}^{\mathrm{a}}$ \\
\hline 10 & 6 & 0.2 & $149.4( \pm 34.9)$ & $57.2(0-92)$ & $65.4(0-94)$ & $\mathrm{ND}^{\mathrm{a}}$ \\
\hline
\end{tabular}

\footnotetext{
${ }^{a}$ In the last three selection rounds $(0.2 \mathrm{mg} / \mathrm{kg}$ BW IVM) the calves were euthanized on day 17 to collect the adult Ostertagia ostertagi from the
} abomasum. 


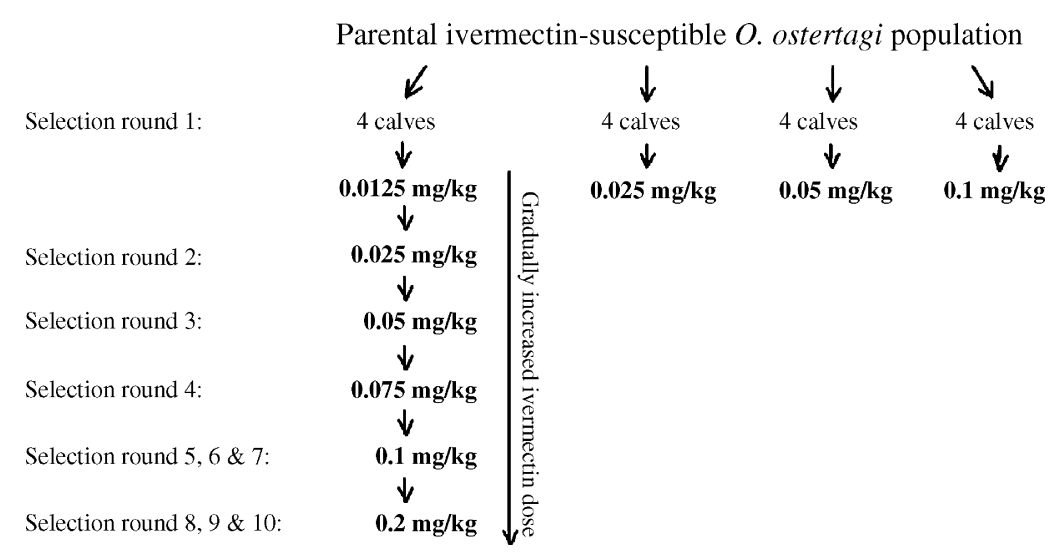

Fig. 1. Schematic diagram of the experimental selection for IVM resistance in Ostertagia ostertagi.

$\mathrm{kg}$ body weight (BW) over ten generations (Fig. 1) until an efficacy of $<90 \%$ with the therapeutic dose $(0.2 \mathrm{mg} /$ $\mathrm{kg} \mathrm{BW}$ ) was reached.

In the last selection round a controlled efficacy test was conducted. Twelve helminth-free calves were randomly divided in two groups. One group was infected with the parental IVMS isolate and one with the progeny of the IVM-resistant (IVMR) isolate from selection round nine. The two groups were treated subcutaneously with the therapeutic IVM dose on day 25 post-infection to assess the efficacy of IVM against the IVMS and IVMR isolates. The IVM dose was calculated based on the mean weight of all the animals on days 24 and 25 post-infection. Faecal samples and blood samples were collected as described above. Individual faecal cultures were made on day 25 postinfection and days 7 and 14 post-treatment. The two groups of calves were euthanized on day 17 after treatment and the $O$. ostertagi were collected from the abomasum.

\subsection{Pharmacokinetic analysis}

In each selection round the IVM levels of all the calves were analyzed in plasma samples collected on days 2, 5 and 10 after IVM treatment. All the blood samples were centrifugated at $3000 \times g$ for $15 \mathrm{~min}$ and plasma was stored at $-20{ }^{\circ} \mathrm{C}$ until analysis. The IVM plasma concentrations were determined by high performance liquid chromatography (HPLC) with automated solid phase extraction and fluorescence detection according to a previously described method (Alvinerie et al., 1993; Lifschitz et al., 2000). The limit of quantification of the IVM analysis method was $0.1 \mathrm{ng} / \mathrm{ml}$ and the coefficient of variation was $3.5 \%$. The areas under the concentration-time curves (AUC) for IVM in plasma were calculated by the linear trapezoidal rule and expressed as ng day $\mathrm{ml}^{-1}$. A Spearman rank correlation test was used to assess the relationship between the administered IVM dose and the bovine plasma concentration of IVM (AUC). Probability $(P)$ values $<0.01$ were considered to indicate significant correlations.

\subsection{Efficacy of ivermectin}

The faecal egg output was determined using a modified McMaster technique (Thienpont et al., 1979) combined with the Cornell-Wisconsin technique (Egwang and Slocombe, 1981) with a sensitivity of 12.5 eggs per gram (EPG). The percentage efficacy of the IVM treatment was assessed by the new individually based faecal egg count reduction test (FECRT) proposed by Cabaret and Berrag (2004). This method is based on an individual evaluation of the egg counts before and after treatment without untreated controls and where each calf serves as its own control. The equation of the formula used to determine the percentage reduction in FEC is: $i$ FECRT $=(1 / n) \sum 100\left(1-\left[T_{i_{2}} / T_{i_{1}}\right]\right)$, where $T_{i_{2}}$ is post-treatment and $T_{i_{1}}$ is pre-treatment egg count in host $i$ from a total $n$ calves. IVM resistance was defined as a less than 95\% reduction in FEC post-treatment (Coles et al., 1992, 2006). As noted above, the relationship between the IVM efficacy and the bovine plasma concentration of IVM (AUC) was assessed. Probability $(P)$ values $<0.05$ were considered to indicate significant correlations.

In the last selection round the IVM efficacy was also assessed by the reduction in larval counts and by the worm counts of the treated IVMS- and IVMR-infected calves. To assess the reduction in larval counts $1.5 \%$ of the larval cultures (day 25 post-infection, days 7 and 14 post-treatment) of each calf was counted and the same formula as for the FECRT was used. The two groups of calves were euthanized on day 17 after treatment. 


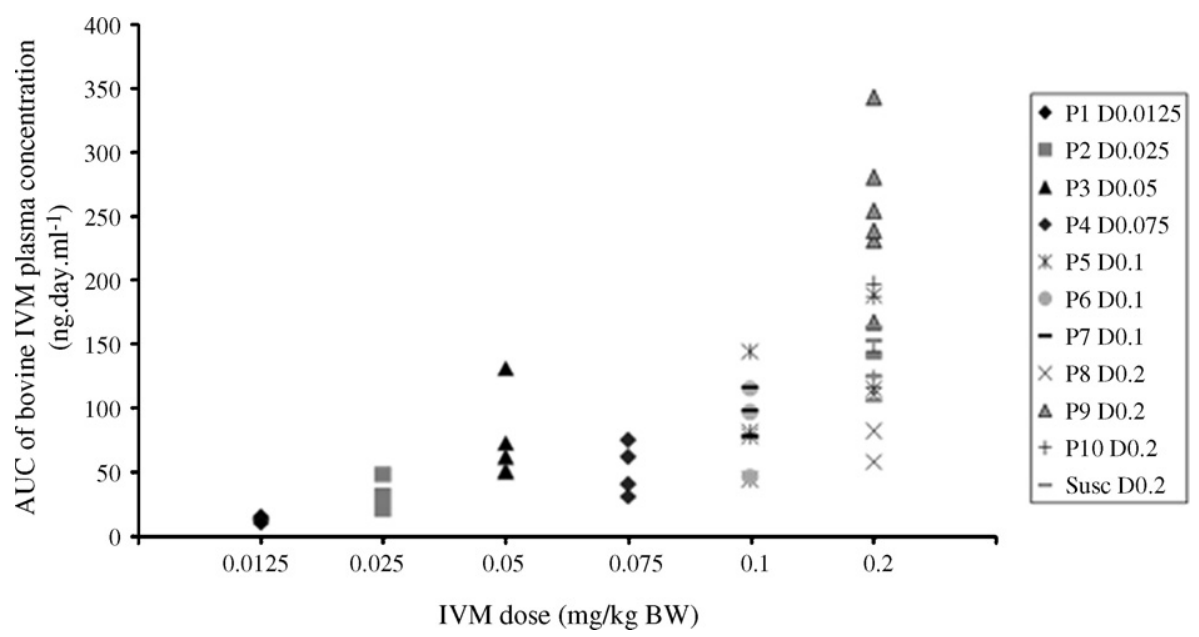

Fig. 2. The individual bovine plasma concentration of ivermectin after subcutaneous administration.

Necropsy, abomasal washing and abomasal digests (HCl-pepsin) were done according to standard techniques (Ritchie et al., 1966; MAFF, 1986). The total $O$. ostertagi worm burdens were estimated by counting $2 \%$ of the abomasal washings and digests of each calf.

\section{Results}

In the first selection round, the treatment with the 0.1 and $0.05 \mathrm{mg} / \mathrm{kg}$ IVM against the IVMS isolate was $100 \%$ effective on days 7, 14 and 21 post-treatment. $O$. ostertagi eggs were only recovered after treatment with the two lowest IVM doses. The $0.025 \mathrm{mg} / \mathrm{kg}$ IVM reduced the FEC by $98 \%, 99 \%$ and $100 \%$ on days 7,14 and 21, respectively. The reduction in FEC with $0.0125 \mathrm{mg} / \mathrm{kg}$ BW IVM dose was $95 \%, 88 \%$ and $93 \%$ on days 7,14 and 21 , respectively. The larvae that survived the $0.0125 \mathrm{mg} / \mathrm{kg} \mathrm{BW}$ IVM dose were used for further selection (Table 1).

The treatment efficacies on days 7, 14 and 21 in the sequential selection rounds are summarized in Table 1 .

In the 10th selection round a controlled efficacy test was conducted. The treatment with the therapeutic IVM dose $(0.2 \mathrm{mg} / \mathrm{kg} \mathrm{BW})$ was $100 \%$ effective against the IVMS isolates since no eggs were detected in the faeces on days 7 and 14 after treatment and no worm burdens in the abomasum were found in the treated IVMS animals. For the IVMR isolate, IVM reduced the FEC by $57 \%$ and $65 \%$ at days 7 and 14 post-treatment, respectively. All the treated IVMR-infected calves had $O$. ostertagi worm burdens ranging from 50 to 4800 , with a geometric mean of 590. The efficacy of IVM against the IVMR isolate, based on the pre- and post-treatment larval counts was $89 \%$ and $59 \%$ on days 7 and 14 posttreatment, respectively. In contrast, the reduction in larval counts for the IVMS isolate was 100\% confirming the IVM-susceptibility of the parental IVMS $O$. ostertagi isolate.

The mean AUC values for the IVM plasma concentration are presented in Table 1. A significant correlation was observed between the administered IVM doses and the IVM plasma concentrations $(R=0.844, P<0.01)$ in the 10 passages. However, large individual variations in the IVM plasma concentrations were present within the same treatment doses (Fig. 2). In the selection rounds with the therapeutic treatments the mean AUC value for IVM varied from 111.1 to $252.9 \mathrm{ng}$ day $\mathrm{ml}^{-1}$ for the IVMRinfected calves (Table 1). In the IVMR-infected calves of the controlled efficacy test a significant positive correlation $(R=0.771, P<0.05)$ was demonstrated between the IVM plasma concentration (AUC value) and IVM efficacy on day 7 post-treatment. However, no significant correlation was found on day 14 posttreatment $(R=0.714, P>0.05)$. The IVMS-infected calves treated with the therapeutic IVM dose had a mean AUC value for IVM of $138.3 \mathrm{ng}^{\text {day } \mathrm{ml}^{-1}}$ and showed a similar individual variability (S.D. $2 \pm 0.4$ ).

\section{Discussion}

In the present study an IVM-susceptible $O$. ostertagi population was selected for IVM resistance by repeatedly exposing the population to subtherapeutic and therapeutic levels of IVM over 10 generations. While IVM was $100 \%$ effective against the susceptible IVMS $O$. ostertagi isolate, the efficacy against the resistant IVMR 0 . ostertagi isolate was $57 \%$ and $65 \%$ on days 7 and 14 post-treatment, respectively. These results were supported by the adult worm burdens. 
$O$. ostertagi were recovered post-treatment in the abomasum of IVMR-infected calves, but no adult worms were found in IVMS-infected calves.

Surprisingly, a large individual variability in IVM efficacy (0-92\%) was demonstrated in the IVMRinfected calves in selection round 10. Several studies have described a strong relationship between the efficacy of ML's and the drug concentration (Lanusse and Prichard, 1993; Baggot and McKellar, 1994). Furthermore, the plasma concentration is closely related to the IVM concentration in the target tissues such as the abomasum (Lifschitz et al., 2000; Lespine et al., 2005). Therefore, it is possible that the individual variability in efficacy in the last selection round is caused by the individual variability in IVM concentrations. In contrast, despite a similar variability in the AUC value for IVM in the IVMS-infected calves, treatment with the therapeutic dose was $100 \%$ effective in all the calves. Although a significant correlation was observed between the administered IVM doses and the IVM plasma concentrations, large variations in plasma concentration were present within the same treatment doses. A similar pharmacokinetic variability in the IVM plasma profiles has also been observed in other studies (McKellar and Benchaoui, 1996; Lanusse et al., 1997) and can be attributed to differences in breed, the site of IVM injection (muscle or fat tissue), the extent and rate of absorption, availability of the drug, metabolism and body composition, diet intake and body condition (Hennessy and Alvinerie, 2002).

Despite the fact that IVM resistance can be induced in $O$. ostertagi, as shown in the present experiment, there are very few reports on IVM resistance in $O$. ostertagi in the field. The basic population biology of $O$. ostertagi and the selection pressure are likely to play an important role in this (Coles, 2002). The most important reason for the slow development of anthelmintic resistance in cattle is considered to be the lower treatment frequency needed for adult cow, compared to ewes, and the consequent presence of a source of refugia. The selective treatment of only first year calves and the natural resistance of adult cows to nematodes have resulted in a very low level of treatment. For that reason the refugia consist primarily of susceptible worms from untreated second year and older animals. In addition, infective $O$. ostertagi larvae can overwinter in large numbers on the field, which results in a large refugium in the spring and therefore resistance is likely to develop much slower compared to sheep nematodes such as $H$. contortus. Moreover, under usual field conditions, adult $O$. ostertagi worms only survive for a relatively short period (25-50 days) and produce less egg compared to $C$. oncophora in cattle and $H$. contortus in sheep. Therefore $O$. ostertagi worms that survive the treatment could have a relatively small advantage over susceptible worms. In contrast, adult $H$. contortus in sheep can persist for many months giving a large advantage to resistant worms to produce the next generation (Coles, 2002). In addition, the IVM concentration that $O$. ostertagi experiences in the abomasal mucosa is higher than in the intestine, the target site of C. oncophora (Lifschitz et al., 2000). This is likely to be the reason why $C$. oncophora is the doselimiting species (Coles, 2002). It was therefore expected that $C$. oncophora would be the first genus showing ML resistance in cattle (Coles, 2002).

On the other hand, the apparent lack of anthelmintic resistance in $O$. ostertagi can also be explained by the lack of sensitive detection tests (Coles, 2002). To date, the detection of anthelmintic resistance in field surveys is mainly based on the in vivo FECRT (Coles et al., 1992). Martin et al. (1989) demonstrated that the FECRT only detects benzimidazole (BZ) resistance when the frequency of the resistance alleles is greater than $25 \%$ in a population. Although the genetic basis of ML resistance and consequent the detection level is different from BZ resistance, the FECRT most likely detects IVM resistance only when the frequency of the resistance alleles is high and significant treatment failure occurs. The lack of sensitive tests means that the detection of anthelmintic resistance is not possible at an early stage and we are not able to follow the spread of resistance alleles. However, the development of sensitive and reliable molecular diagnostic tests requires knowledge of the mechanisms of resistance and this is currently lacking. Therefore a good starting point for further investigation would be to compare the molecular background of the IVM-susceptible parental isolate and the laboratory IVM-resistant $O$. ostertagi isolate in order to understand better the mechanisms of IVM resistance in O. ostertagi. Candidate genes that have been associated with ML resistance in other trichostrongylid nematodes will be analysed in $O$. ostertagi.

One should also take into account that a laboratoryselected isolate not necessarily reflects a resistant field $O$. ostertagi isolate. Different selection protocols can select for different resistance phenotypes and, presumably, genotypes (Gill et al., 1998). It is likely that selection with doses below the recommended dose rate tends to reveal all the potential resistance-associated genes, but fails to distinguish which gene might have the largest effect in field-selected resistance (Prichard, 2001; Gilleard and Beech, 2007). Another issue that needs to be considered is the possibility that different 
isolates of $O$. ostertagi may have different mechanisms of resistance. It will therefore be important to validate results obtained with the laboratory-selected isolate against resistant isolates from the field.

\section{Acknowledgements}

This research was funded by a $\mathrm{PhD}$ grant of the 'Institute for the Promotion of Innovation through Science and Technology in Flanders (IWT-Vlaanderen)' and supported by the European Framework Program 6 (FP6, FOOD-2004-T5.4.6.6) (PARASOL-project). PG is the recipient of a Marie Curie reintegration grant (no. 028870) and is a Postdoctoral Fellow of the Fund for Scientific Research-Flanders (Belgium) (F.W.O.-Vlaanderen). The authors would like to thank Rudy Cooman for taking care of the animals.

\section{References}

Alvinerie, M., Sutra, J.F., Galtier, P., 1993. Ivermectin in goat plasma and milk after subcutaneous injection. Vet. Res. 24, 417-421.

Anziani, O.S., Zimmermann, G., Guglielmone, A.A., Vazquez, R., Suarez, V., 2001. Avermectin resistance in Cooperia pectinata in cattle in Argentina. Vet. Rec. 149, 58-59.

Baggot, J.D., McKellar, Q.A., 1994. The absorption, distribution and elimination of anthelmintic drugs: the role of pharmacokinetics. J. Vet. Pharmacol. Ther. 17, 409-419.

Cabaret, J., Berrag, B., 2004. Faecal egg count reduction test for assessing anthelmintic efficacy: average versus individually based estimations. Vet. Parasitol. 121, 105-113.

Coles, G.C., 2002. Cattle nematodes resistant to anthelmintics: why so few cases? Vet. Res. 33, 481-489.

Coles, G.C., Bauer, C., Borgsteede, F.H., Geerts, S., Klei, T.R., Taylor, M.A., Waller, P.J., 1992. World Association for the Advancement of Veterinary Parasitology (W.A.A.V.P.) methods for the detection of anthelmintic resistance in nematodes of veterinary importance. Vet. Parasitol. 44, 35-44.

Coles, G.C., Stafford, K.A., MacKay, P.H., 1998. Ivermectin-resistant Cooperia species from calves on a farm in Somerset. Vet. Rec. $142,255-256$.

Coles, G.C., Watson, C.L., Anziani, O.S., 2001. Ivermectin-resistant Cooperia in cattle. Vet. Rec. 148, 283-284.

Coles, G.C., Jackson, F., Pomroy, W.E., Prichard, R.K., von SamsonHimmelstjerna, G., Silvestre, A., Taylor, M.A., Vercruysse, J., 2006. The detection of anthelmintic resistance in nematodes of veterinary importance. Vet. Parasitol. 136, 167-185.

Echevarria F., Pinheiro A., 1999. Eficiência de anti-helmínticos em bovinos. XI. Seminário Brasileiro de Parasitologia Veterinária, October 24-28, Abstract TL-HB-274.

Egwang, T.G., Slocombe, J.O., 1981. Efficiency and sensitivity of techniques for recovering nematode eggs from bovine faeces. Can. J. Comp. Med. 45, 243-248.

Familton, A.S., Mason, P., Coles, G.C., 2001. Anthelmintic-resistant Cooperia species in cattle. Vet. Rec. 149, 719-720.

Fiel, C.A., Saumell, C.A., Steffan, P.E., Rodriguez, E.M., 2001. Resistance of Cooperia to ivermectin treatments in grazing cattle of the Humid Pampa, Argentina. Vet. Parasitol. 97, 211-217.
Gasbarre, L.C., Smith, L.L., Lichtenfels, J.R., Pilitt, P.A., 2004. The identification of cattle nematode parasites resistant to multiple classes of anthelmintics in a commercial cattle population in the U.S.In: The American Association of Veterinary Parasitologists. 49th Meeting, Philidelphia, PA, July 24-28 (abstract 44).

Geary, T.G., 2005. Ivermectin 20 years on: maturation of a wonder drug. Trends Parasitol. 21, 530-532.

Gill, J.H., Kerr, C.A., Shoop, W.L., Lacey, E., 1998. Evidence of multiple mechanisms of avermectin resistance in Haemonchus contortus - comparison of selection protocols. Int. J. Parasitol. 28, 783-789.

Gilleard, J.S., Beech, R.N., 2007. Population genetics of anthelmintic resistance in parasitic nematodes. Parasitology 134 (08), 11331147 (special issue).

Hennessy, D.R., Alvinerie, M.R., 2002. Pharmacokinetics of the macrocyclic lactones: conventional wisdom and new paradigms. In: Vercruysse, J., Rew, R.S. (Eds.), Macrocyclic Lactones in Antiparasitic Therapy. CABI Publishing, UK, pp. 97-123.

Jackson, F., Coop, R.L., 2000. The development of anthelmintic resistance in sheep nematodes. Parasitology 120 (Suppl.), S95S107.

Kaplan, R.M., 2004. Drug resistance in nematodes of veterinary importance: a status report. Trends Parasitol. 20, 477-481.

Lanusse, C.E., Prichard, R.K., 1993. Relationship between pharmacological properties and clinical efficacy of ruminant anthelmintics. Vet. Parasitol. 49, 123-158.

Lanusse, C., Lifschitz, A., Virkel, G., Alvarez, L., Sanchez, S., Sutra, J.F., Galtier, P., Alvinerie, M., 1997. Comparative plasma disposition kinetics of ivermectin, moxidectin and doramectin in cattle. J. Vet. Pharmacol. Ther. 20, 91-99.

Lespine, A., Alvinerie, M., Sutra, J.F., Pors, I., Chartier, C., 2005. Influence of the route of administration on efficacy and tissue distribution of ivermectin in goat. Vet. Parasitol. 128, 251260.

Lifschitz, A., Virkel, G., Sallovitz, J., Sutra, J.F., Galtier, P., Alvinerie, M., Lanusse, C., 2000. Comparative distribution of ivermectin and doramectin to parasite location tissues in cattle. Vet. Parasitol. 87, 327-338.

Loveridge, B., McArthur, M., McKenna, P.B., Mariadass, B., 2003. Probable multigeneric resistance to macrocyclic lactone anthelmintics in cattle in New Zealand. NZ. Vet. J. 51, 139-141.

MAFF, 1986. Manual of Veterinary Parasitological Techniques, 3rd ed. HMSO, London, 160.

Martin, P.J., Anderson, N., Jarrett, R.G., 1989. Detecting benzimidazole resistance with faecal egg count reduction tests and in vitro assays. Aust. Vet. J. 66, 236-240.

Mason, P.C., McKay, C.H., 2006. Field studies investigating anthelmintic resistance in young cattle on five farms in New Zealand. NZ. Vet. J. 54, 318-322.

McKellar, Q.A., Benchaoui, H.A., 1996. Avermectins and Milbemycins. J. Vet. Pharmacol. Ther. 19, 331-351.

McKellar, Q.A., Jackson, F., 2004. Veterinary anthelmintics: old and new. Trends Parasitol. 20, 456-461.

Mejia, M.E., Fernandez Igartua, B.M., Schmidt, E.E., Cabaret, J., 2003. Multispecies and multiple anthelmintic resistance on cattle nematodes in a farm in Argentina: the beginning of high resistance? Vet. Res. 34, 461-467.

Prichard, R.K., 2001. Genetic variability following selection of Haemonchus contortus with anthelmintics. Trends Parasitol. 17, 445453.

Ritchie, J.D., Anderson, N., Armour, J., Jarrett, W.F., Jennings, F.W., Urquhart, G.M., 1966. Experimental Ostertagia ostertagi infec- 
tions in calves: parasitology and pathogenesis of a single infection. Am. J. Vet. Res. 27, 659-667.

Suarez, V.H., Cristel, S.L., 2007. Anthelmintic resistance in cattle nematode in the western Pampeana region of Argentina. Vet. Parasitol. 144, 111-117.

Thienpont, D., Rochette, F., Van Parijs, O.F.J., 1979. Diagnosing Helminthiasis by Coprological Examination, 187. Janssen Research Foundation, Beerse.
Vermunt, J.J., West, D.M., Pomroy, W.E., 1996. Inefficacy of moxidectin and doramectin against ivermectin-resistant Cooperia spp. of cattle in New Zealand. NZ. Vet. J. 44, 188193.

Waghorn, T.S., Leathwick, D.M., Rhodes, A.P., Jackson, R., Pomroy, W.E., West, D.M., Moffat, J.R., 2006. Prevalence of anthelmintic resistance on 62 beef cattle farms in the North Island of New Zealand. NZ. Vet. J. 54, 278-282. 